\title{
Optimalisasi Jasa Antar Koridor Pelayanan Trans Metro Pekanbaru Berbasis Persepsi Penumpang
}

\author{
Muchammad Zaenal Muttaqin ${ }^{1}$ \\ ${ }^{1}$ Program Studi Teknik Sipil, Universitas Islam Riau \\ Jalan Kaharuddin Nasution No. 113 Perhentian Marpoyan Pekanbaru 28284
}

\begin{abstract}
Abstrak
Dalam upaya menciptakan suatu system transportasi yang baik di kota Pekanbaru, keberadaan Trans Metro Pekanbaru sebagai moda transportasi utama amat perlu dikembangkan secara konsisten dan menerus. Setiap rute pelayanan tersebut memiliki karakteristik tersendiri terkait jenis pelayanan dan karakteristik rute yang dilayani. Tujuan dari penelitian ini adalah untuk mengetahui kualitas pelayanan dalam perbandingan rute pelayanan agar menjadi pertimbangan dalam perhitungan kualitas pelayanan angkutan umum Trans Metro Pekanbaru. Batasan dari penelitian ini adalah hanya membandingkan dua rute perjalanan, yakni rute 2 yang menghubungkan Terminal BRPS-Kulim (rute komersial) dan rute 3 yang menghubungkan Ramayana-UIN Suska Panam (Rute komersial dan pendidikan). Analisis IPA (Importance-Performance Analysis) digunakan untuk mengetahui kualitas pelayanan antar rute perjalanan Trans Metro Pekanbaru sehingga memudahkan dalam penentuan prioritas bagi Trans Metro dalam melakukan peningkatan pelayanannya untuk setiap rute pelayanan. Sampel penelitian ini adalah 279 orang untuk setiap rute perjalanan. Hasil penelitian menunjukkan bahwa terdapat perbedaan pada setiap rute perjalanan. Secara umum, Hal ini dikarenakan penumpang memberi alasan tentang ketertarikan untuk menggunakan Trans Metro Pekanbaru adalah lebih menarik dibanding moda yang lain. Sehingga, strategi peningkatan kualitas dari segi waktu pelayanan menjadi perhatian serius bagi Trans Metro Pekanbaru untuk mencapai sebuah system transportasi yang lebih baik dan menuju transportasi yang berkelanjutan di kota Pekanbaru.
\end{abstract}

Kata kunci: System transportasi, Persepsi, Importance-Performance Analysis 


\section{PENDAHULUAN}

\section{Latar Belakang}

Transportasi bukanlah menjadi kebutuhan utama bagi masyarakat, namun sebagai turunan dari kebutuhan utama yang dibutuhkan oleh masyarakat. Pada saat ini, orang banyak menggunakan kendaraan pribadi untuk melakukan kegiatan transportasi. Hal ini terjadi karena tingkat fleksibilitas oleh kendaraan pribadi jika dibandingkan dengan angkutan yang lainnya. dari transportasi umum karena fleksibilitas yang tinggi. Di sisi lain, kendaraan pribadi membuat dampak yang negatif bagi kehidupan, seperti polusi, kemacetan, kebisingan dll. Hal ini juga diperkuat oleh banyak peneliti, seperti Steg (2001), Eriksson (2011) dan Litman (2010).

Sistem transportasi yang berkelanjutan merupakan salah satu solusi dalam permasalahan transportasi pada saat ini. Kenworthy (2014) dan Gerike et al ( 2013) memiliki pendapat yang sama bahwa transportasi yang berkelanjutan dapat diwujudkan salah satunya dengan pengembangan suatu system angkutan umum yang yang berkelanjutan dan mampu menunjang pembangunan di sebuah wilayah. Angkutan umum sendiri berperan dengan menyediakan sarana mobilitas yang efektif serta efiisien bagi masyarakat.

Kegiatan komuter adalah salah satu aktivitas pejalanan sehari-hari terutama dalam kasus ini adalah mahasiswa dalam kehidupan mereka. Transportasi yang berkelanjutan untuk aktivitas komuter pada mahasiswa dapat dicapai dengan pengembangan dari transportasi umum. Evaluasi terhadap tingkat harapan dan persepsi penumpang angkutan umum yang diperoleh mampu menarik lebih banyak penumpang. Munawar (2006) menyatakan bahwa angkutan umum akan membuat suatu moda transportasi alternative untuk transportasi dan kualitas dari pelayanannya terkait dengan harapan dari para pengguna angkutan umum. Peningkatan kualitas pelayanan dari transportasi umum dapat membuat masyarakat, terutama mahasiswa cenderung memilih angkutan umum sebagai moda transportasi untuk aktivitas komuter.

\section{Tujuan}

Penelitian ini membahas tentang pelayanan Trans Metro Pekanbaru sebagai salah satu angkutan umum di kota Pekanbaru berdasarkan karakteristik tiap rute. Penumpang sebagai konsumen akhir memiliki peran yang sangat penting dalam perkembangan Trans Metro itu sendiri di Pekanbaru. Faktor pemilihan moda transportasi sendiri dipengaruhi oleh faktor persepsi masyarakat berdasar kualitas pelayanan yang diberikan oleh moda transportasi menurut sudut pandang mahasiswa.

Hasil dari penelitian ini diharapkan dapat memberikan informasi mengenai karakteristik pelayanan Trans Metro berdasar karakteristik rute agar menjadi bahan pertimbangan oleh pihak terkait di dalam kebijakan investasi perencanaan transportasi dan pengembangan moda transportasi di Kota Pekanbaru terutama untuk kalangan mahasiswa., kemacetan,

\section{Batasan Penelitian}

Dalam suatu penelitian, batasan penelitian dianggap perlu dicantumkan agar hasil yang didapat sesuai dengan tujuan yang diharapkan. Dalam penelitian ini, batasan yang digunakan antara, lain,

a. Penelitian ini didasarkan hanya terhadap dua rute Trans Metro Pekanbaru, yakni rute 2 ( rute BRPS-Kulim) dan rute 3 (Ramayana-UIN Suska Panam).

b. Dalam menganalisis pelayanan Trans Metro, hanya menggunakan persepsi dari konsumen saja, tanpa melakukan verifikasi terhadap karakteristik pelayanan yang dilakukan oleh pihak operator Trans Metro Pekanbaru.. 
c. Parameter yang digunakan di dalam analisis IPA hanya 15 parameter yang sisapat dari sumber pustaka.

\section{Landasan Teori}

Albalate dan G.Bell (2010) memiliki penjelasan bahwa transportasi sebagai suatu alat koneksi antara dua atau lebih tempat yang berbeda akan memerankan posisi yang penting terutama terhadap mobilitas. Hal ini akan mempengaruhi terhadap lingkungan perkotaan itu sendiri. Dalam suatu perencanaan transportasi, dibutuhkan suatu pendekatan transportasi yang sesuai dengan keadaan wilayah ataupun objek perencanaan itu sendiri. Pendekatan secara system dianggap menjadi salah satu pendekatan yang tepat untuk perencanaan transportasi. Djakfar dkk (2010) menyatakan bahwa di dalam pendekatan system, suatu perencanaan harus dilakukan analisis yang menyeluruh atau semua faktor yang berhubungan dengan permasalahan yang ada harus dipertimbangkan. Oleh karena itu, sangatlah perlu dilakukan suatu analisis mendalam mengenai karakteristik system transportasi yang ada guna perencanaan transportasi yang lebih baik.

Kualitas pelayanan telah didefinisikan sebagai nilai yang diterima oleh pelanggan (konsumen) dari produk atau jasa yang diberikan oleh penyedia jasa (provider). L.A. Guedesa (1998) yang disadur oleh Sultana and Rana (2010) menjelaskan bahwa jasa merupakan suatu proses negosiasi antara konsumen sebagai penilai jasa dan penyedia jasa sebagai sumber jasa dimana sumber daya dan manajemen telah dilakukan dengan seimbang antara persepsi kualitas jasa (produk) dan kepuasan kerja para karyawannya. Parasuraman, et al (1990) menjelaskan bahwa kualitas pelayanan bergantung pada bagaimana pelayanan dari operator yang mampu memenuhi ekspektasi konsumen. Persepsi dari konsumen menentukan bagaimana kinerja dari pelayanan jasa tersebut. Persepsi merupakan salah satu komponen dalam suatu pengalaman pengguna jasa yang berperan di dalam kepuasan dan membangun kualitas pelayanan dari jasa tersebut. Oliver (1997) yang disadur oleh Pedersen et al (2011) menyatakan bahwa kepuasan konsumen merupakan salah satu penilaian dari pandangan konsumen bagaimana jasa tersebut mampu memenuhi ekspektasi konsumen. Joewono dan Kubota (2007) menyatakan bahwa kinerja menjadi salah satu aspek penting untuk mengevaluasi operator angkutan umum, bukan hanya tentang profitabilitas. Kinerja membuat efek kepuasan dari pelanggan. Loyalitas dan ketertarikan konsumen dalam penggunaan pelayanan jasa menjadi tujuan akhir dari kepuasan konsumen yang didapat.

Importance-Performance analysis (IPA) adalah suatu analisis statistik yang menunjukkan hubungan antara performa dari suatu jasa pelayanan dan nilai kepentingan dari pelanggan (dalam kasus ini adalah penumpang) yang berguna untuk mengetahui tingkat prioritas guna meningkatkan kualitas pelayanan jasa yang ada. Analisis ini sangat sederhana, namun mampu menunjukkan suatu identifikasi parameter yang perlu ditingkatkan, diperbaiki, atau justru ditiadakan di masa depan. Analisis ini ditemukan oleh Martilla and James pada tahun 1977, dimana melalui suatu penggambaran grafik untuk memudahkan penggambaran parameter performa dan kepentingan yang kemudian dihubungkan satu sama lain. Grafik tersebut tergambar dalam gambar di bawah ini,

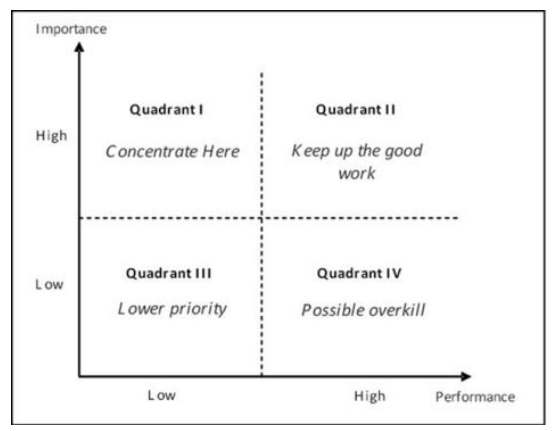

Gambar 1. Grafik analisis IPA (Sumber : Martilla dan James,1977) 


\section{METODOLOGI PENELITIAN}

\section{Pendekatan Metode}

Analisis yang dilakukan adalah bertujuan untuk mengetahui performa dari pelayanan Trans Metro Pekanbaru terhadap penumpang terutama pada rute 2 dan rute 3. Pendekatan metode yang dilakukan ialah secara kualitatif melalui metode Likert dilakukan untuk menganalisis performansi terhadap pelayanan moda transportasi yang digunakan serta mendapatkan gambaran potensi bagaimana moda tersebut dapat mempengaruhi di dalam pemilihan moda transportasi tersebut. Sedangkan pada tahapan analisis, digunakan analisis IPA guna mengetahui karakteristik performansi yang perlu ditingkatkan oleh pihak Trans Metro untuk setiap rute perjalanan.

\section{Jenis dan Pengumpulan data}

Penelitian ini menggunakan data survei kuesioner sebagai data utama. Objek penelitian ini adalah penumpang yang menggunakan jasa Trans Metro sebagai moda transportasi. Secara umum, data yang dibutuhkan dalam penelitian ini terdiri dari dua kelompok, yaitu data primer dan data sekunder. Data Primer didapat melalui penyebaran kuisioner secara acak kepada penumpang, baik pada rute 2 mapun rute 3 .. Kuisioner ini berisi tiga komponen, yakni komponen pertama yang menyangkut karakteristik penumpang Trans Metro Pekanbaru. Komponen kedua berisi persepsi mahasiswa mengenai performansi layanan Trans Metro Pekanbaru. Sedangkan komponen ketiga, berisi parameter nilai harapan penumpang terhadap layanan tersebut. Cara pengumpulan data pada penelitian ini ialah mahasiswa yang menjadi responden diminta untuk mengisi kuisioner tersebut didampingi oleh surveyor, kemudian kuisioner akan langsung dibawa kembali oleh surveyor setelah semua pertanyaan telah diisi. Perencanaan jumlah sampel dalam penelitian adalah berdasarkan Roscoe (1975) yang dikutip Uma Sekaran
(2006) dimana acuan umum untuk menentukan ukuran sampel ialah sebagai berikut,

a. Ukuran sampel lebih dari 30 dan kurang dari 500 adalah tepat untuk kebanyakan penelitian

b. Jika sampel dipecah ke dalam subsampel (pria/wanita, junior/senior, dan sebagainya), ukuran sampel minimum 30 untuk tiap kategori adalah tepat

c. Dalam penelitian mutivariate (termasuk analisis regresi berganda), ukuran sampel sebaiknya 10x lebih besar dari jumlah variabel dalam penelitian

d. Untuk penelitian eksperimental sederhana dengan kontrol eskperimen yang ketat, penelitian yang sukses adalah mungkin dengan ukuran sampel kecil antara 10 sampai dengan 20 .

Di dalam penelitian ini, digunakan ukuran antara $30-500$ kuesioner guna mendapatkan data penumpang Trans Metro, baik pada rute 2 dan rute 3 pada perjalanan Trans Metro Pekanbaru tersebut.

\section{ANALISIS DAN PEMBAHASAN}

Deskripsi Umum

Penelitian ini menggunakan data kuesioner dari penumpang Trans Metro Pekanbaru (TMP) terutama pada rute 2 dan rute 3 . Data yang telah didapat sebanyak 279 sampel pada masing-masing rute perjalanan. Data kuesioner tersebut telah dilakukan uji validitas dan uji reliabilitas guna kelayakan di dalam analisa. Berdasar uji tersebut, kedua kelompok data memiliki nilai valuasi sebesar 0.98 yang berarti telah dapat digunakan dalam tahapan analisa data berikutnya. 


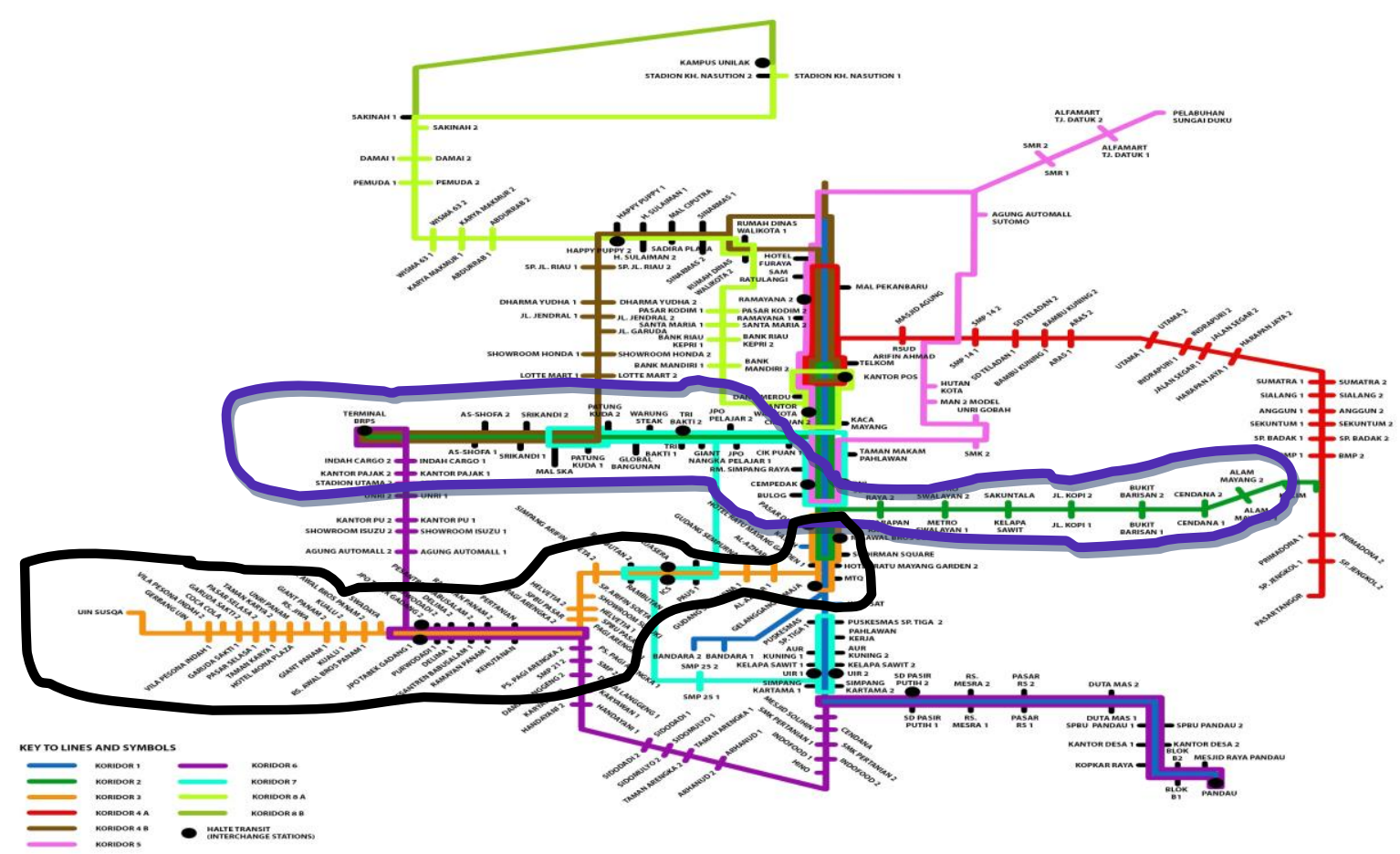

Keterangan : $\quad=$ Rute $2($ BPRS-Kulim)
$\quad=$ Rute 3 ( Ramayana - UIN Suska Panam)

Gambar 2. Rute Trans Metro Pekanbaru

Deskripsi data penelitian menunjukkan bahwasanya pengguna angkutan umum rerata merupakan pengguna yang memiliki rentang pendapatan kurang dari 2 juta rupiah. Kelompok pada rentang ini merupakan rentang pendapatan yang masih kurang dari UMR Kota Pekanbaru, yakni 2,5 juta rupiah, atau dapat dikatakan sebagai kelompok menengah ke bawah. Hal ini menjadi pertanda bahwa konsumen yang dilayani oleh angkutan umum sebagian besar adalah kelompok masyarakat pengguna ke bawah yang diasumsikan tidak memiliki pilihan alternative yang lain dalam melakukan transportasi.

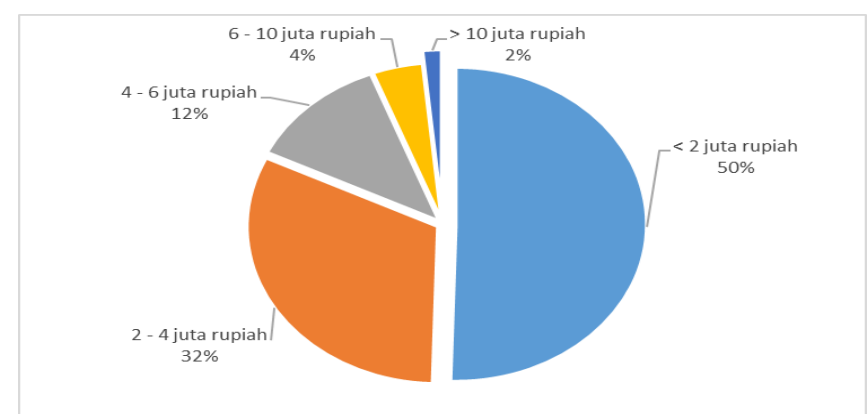

Gambar 3. Rentang pendapatan penumpang rute 2 dan rute 3 TMP

Pembahasan lebih dalam terkait hubungan pendapatan terhadap angkutan umum terlihat pada hubungan pendapatan dengan frekuensi penggunaan angkutan umum serta penggunaan kendaraan sehari-hari. Tabel 1 menyatakan bahwa pada 
keseluruhan kelompok rentang pendapatan, sepeda motor masih menjadi pilihan nomor satu bagi masyarakat sebelum memilih moda transportasi yang lain. Hal ini mendukung pernyataan dari Muttaqin (2018), Irawan dan Sumi (2011) serta Devi (2015), yang menyatakan bahwa dominasi kendaraan bermotor terutama sepeda motor masih tergolong dominan di Indonesia, selain dikarenakan supply sepeda motor yang semakin banyak ragam, factor kemudahan dan fleksibilitas moda sepeda motor menjadi salah satu bagian penyebab dominasi tersebut. Oleh karena itu, pengembangan angkutan umum, baik kuantitas maupun kualitas masih sangat dibutuhkan guna menekan pertumbuhan kendaraan bermotor dan mencapai sustainability di dalam sektor transportasi kota.

Tabel 1. Rentang pendapatan,penggunaaan kendaraan dan frekuensi angkutan umum

\begin{tabular}{lccccc}
\hline & \multicolumn{5}{c}{ Rentang pendapatan (Rupiah) } \\
\cline { 2 - 6 } & $<2$ juta & $\begin{array}{c}\mathbf{2}-\mathbf{4} \\
\text { juta }\end{array}$ & $\begin{array}{c}\mathbf{4}-\mathbf{6} \\
\text { juta }\end{array}$ & $\mathbf{6}$ - 10 juta & $>$ 10 juta \\
\hline Kendaraan sehari-hari & & & & \\
\hline Sepeda & $1.40 \%$ & $2.80 \%$ & $0.00 \%$ & $0.00 \%$ & $0.00 \%$ \\
\hline Motor & $42.30 \%$ & $51.70 \%$ & $67.60 \%$ & $50.00 \%$ & $55.60 \%$ \\
\hline Mobil & $2.40 \%$ & $3.90 \%$ & $8.80 \%$ & $25.00 \%$ & $22.20 \%$ \\
\hline Nebeng Teman & $6.60 \%$ & $2.80 \%$ & $4.40 \%$ & $0.00 \%$ & $0.00 \%$ \\
\hline Angkutan & $26.90 \%$ & $29.40 \%$ & $17.60 \%$ & $25.00 \%$ & $22.20 \%$ \\
\hline Umum & $20.20 \%$ & $9.40 \%$ & $1.50 \%$ & $0.00 \%$ & $0.00 \%$ \\
\hline Lainnya & $100.00 \%$ & $100.00 \%$ & $100.00 \%$ & $100.00 \%$ & $100.00 \%$ \\
\hline Total & & & & \\
\hline Frekuensi penggunaan Angkutan & & & \\
\hline Setiap Hari & $19.23 \%$ & $25.00 \%$ & $11.76 \%$ & $16.67 \%$ & $0.00 \%$ \\
\hline Seminggu 3 kali & $2.80 \%$ & $2.78 \%$ & $2.94 \%$ & $0.00 \%$ & $0.00 \%$ \\
\hline Seminggu 2 kali & $3.50 \%$ & $5.00 \%$ & $8.82 \%$ & $0.00 \%$ & $0.00 \%$ \\
\hline Sebulan sekali & $2.10 \%$ & $1.67 \%$ & $1.47 \%$ & $4.17 \%$ & $11.11 \%$ \\
\hline Tidak menentu & $65.03 \%$ & $50.56 \%$ & $69.12 \%$ & $79.17 \%$ & $88.89 \%$ \\
\hline Seminggu 1 kali & $0.00 \%$ & $5.00 \%$ & $1.47 \%$ & $0.00 \%$ & $0.00 \%$ \\
\hline Kosong & $7.34 \%$ & $10.00 \%$ & $4.41 \%$ & $0.00 \%$ & $0.00 \%$ \\
\hline Total & $100.00 \%$ & $100.00 \%$ & $100.00 \%$ & $100.00 \%$ & $100.00 \%$ \\
\hline
\end{tabular}

Selain itu, table 1 juga menunjukkan bahwasanya pada setiap kelompok rentang pendapatan, penumpang rute 2 dan rute 3 Trans Metro Pekanbaru buksn merupakan pengguna aktif angkutan umum. Frekuensi penggunaan angkutan umum bagi penumpang didominasi oleh tidak menentu, yang berarti penumpang hanya akan menggunakan angkutan umum sebagai moda angkutan alternatif ketika kondisi tidak memenuhi ekspektasi pengguna itu sendiri. Hal ini tidak berhubungan dengan seberapa rentang pendapatan yang dimiliki oleh penumpang. Di sisi yang lain, dari tabel 1 terlihat kecenderungan bahwasanya semakin tinggi pendapatan, maka pilihan untuk menaiki angkutan umum cenderung semakin mengecil. Hal ini menunjukkan bahwasanya keinginan masyarakat untuk memilih angkutan umum semakin kecil ketika pendapatan semakin besar.

Berdasar hasil deskripsi yang lain menunjukkan hasil yang menyatakan 
bahwa penumpang cenderung memilih angkutan Trans Metro Pekanbaru dikarenakan factor keamanan,kenyamanan, dan ramah lingkungan. Hal ini berlaku untuk seluruh rute, baik rute 2 dan rute 3 . Hal ini juga dibuktikan melalui uji-T yang membuktikan bahwasanya tidak adanya perubahan yang signifikan antara kedua rute ( $p$-value >0.05) terkait parameter tersebut. Hal ini menunjukkan bahwasanya alasan penggunaan angkutan umum bagi masyarakat tidak dibatasi oleh rute angkutan umum itu sendiri. Penumpang rute 2 maupun rute 3 Trans Metro Pekanbaru beranggapan bahwa alasan memilih angkutan umum tidak terkait sama sekali dengan jenis rute yang akan dituju, namun lebih kepada kepentingan internal dari penumpang.

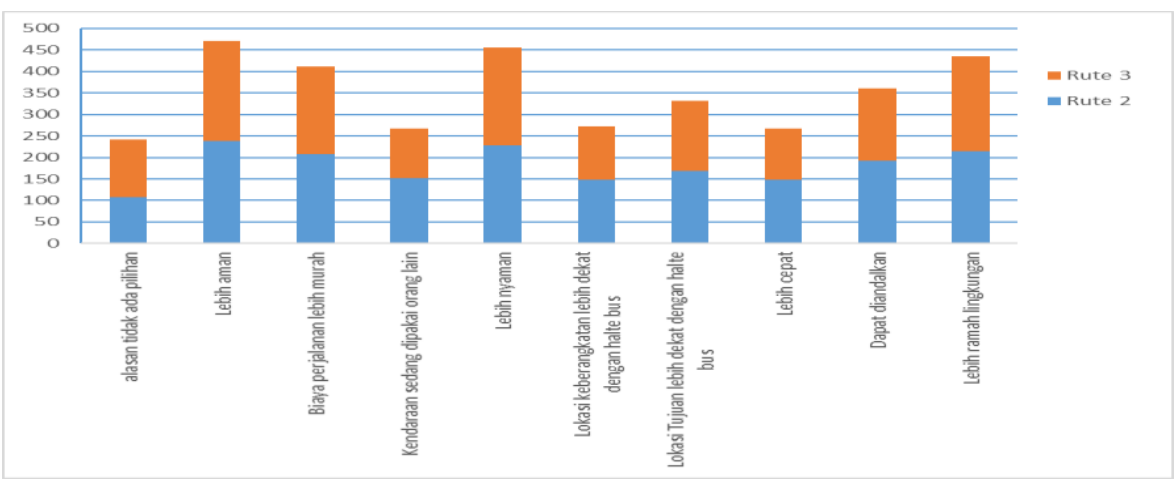

Gambar 3. Alasan Penggunaan Angkutan umum bagi penumpang Trans Metro Pekanbaru

Kualitas Angkutan Umum

Penelitian ini bertujuan untuk mengetahui bagaimana kualitas angkutan umum berbasis persepsi penumpang untuk setiap rute yang diadakan oleh pihak angkutan umum Trans Metro Pekanbaru. Penelitian ini menggunakan 25 parameter sebagai pembanding antar rute angkutan umum Trans Metro (table 2).

Tabel 2. Parameter penelitian

\begin{tabular}{|l|l|}
\hline No & \multicolumn{1}{|c|}{ Parameter } \\
\hline 1 & Lama menunggu bis di halte \\
\hline 2 & Keamanan di dalam halte \\
\hline 3 & $\begin{array}{l}\text { Kedatangan bus sesuai dengan waktu } \\
\text { yang dijadwalkan }\end{array}$ \\
\hline 4 & Kebersihan halte Trans Metro \\
\hline 5 & $\begin{array}{l}\text { Informasi di halte Trans Metro sangat } \\
\text { jelas }\end{array}$ \\
\hline 6 & Keamanan di dalam bus \\
\hline 7 & $\begin{array}{l}\text { Kemudahan akses menuju halte Trans } \\
\text { Metro Pekanbaru }\end{array}$ \\
\hline 8 & $\begin{array}{l}\text { Kenyamanan selama menunggu di dalam } \\
\text { halte }\end{array}$ \\
\hline 9 & $\begin{array}{l}\text { Kemudahan mendapat tempat duduk di } \\
\text { bus }\end{array}$ \\
\hline 10 & Harga Tiket yang terjangkau \\
\hline 11 & Kemudahan mendapatkan tiket \\
\hline 12 & $\begin{array}{l}\text { Pelayanan bus dilakukan dengan cepat } \\
\text { dan responsive }\end{array}$ \\
\hline
\end{tabular}




\begin{tabular}{|l|l|}
\hline No & \multicolumn{1}{|c|}{ Parameter } \\
\hline 13 & Kebersihan di dalam bus \\
\hline 14 & Waktu operasi pelayanan bus \\
\hline 15 & Kenyamanan di dalam bus \\
\hline 16 & $\begin{array}{l}\text { Kepedulian awak bus kepada } \\
\text { penumpang }\end{array}$ \\
\hline 17 & $\begin{array}{l}\text { Karyawan selalu siap melayani } \\
\text { permintaan penumpang }\end{array}$ \\
\hline 18 & Fasilitas di dalam bus \\
\hline 19 & Fasilitas tempat duduk \\
\hline 20 & Karyawan baik, ramah dan sopan \\
\hline 21 & $\begin{array}{l}\text { Karyawan memberi informasi yang jelas } \\
\text { pada penumpang }\end{array}$ \\
\hline 22 & Sikap supir dalam berkendara \\
\hline 23 & kualitas secara umum \\
\hline 24 & Penampilan awak bus \\
\hline 25 & Armada bus sudah modern dan mutakhir \\
\hline
\end{tabular}

Hasil analisis melalui analisis IPA (Importance Performance Analysis) menunjukkan bahwasanya dalam rute 2 dan rute 3 angkutan umum Trans Metro Pekanbaru, berada pada Kuadran I dan II. Hal ini menunjukkan bahwasanya kualitas angkutan umum masih butuh untuk selalu ditingkatkan pada setiap rute perjalanannya. Dari 25 parameter yang diteliti, rute 2 maupun rute 3 menunjukkan bahwasanya terdapat 8 parameter yang terdapat pada kuadran 1 (butuh perhatian
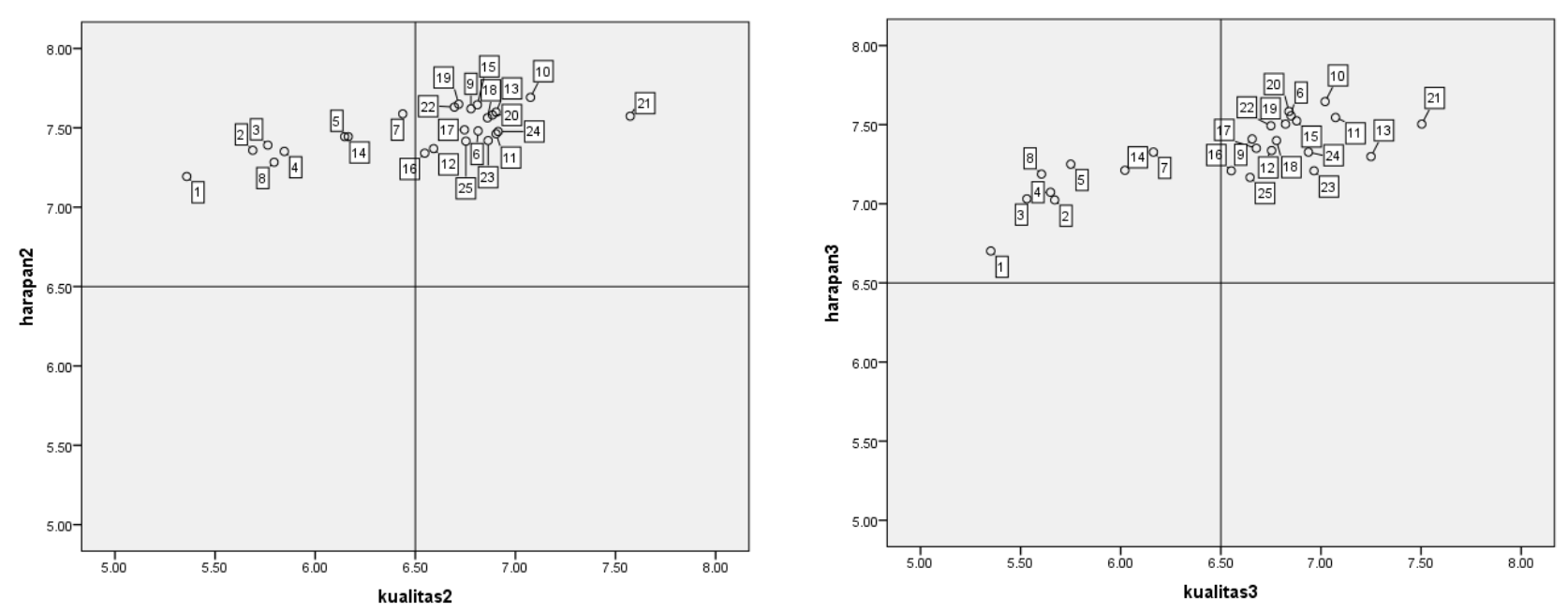

Gambar 4. Grafik analisis IPA rute 2 (kiri) dan rute 3 (kanan) Trans Metro Pekanbaru 


\section{KESIMPULAN}

V. Suatu pengetahuan mengenai persepsi penumpang dalam penentuan kualitas pelayanan Trans Metro Pekanbaru adala sesuatu yang penting dalam pencapaian system transportasi yang berkelanjutan terutama dalam wilayah perkotaan. Dari segi teori, kualitas pelayanan suatu jasa mampu menghasilkan suatu profitabilitas secara tidak langsung akibat kepuasan konsumen serta kesetiaannya dalam penggunaan jasa tersebut. Dari segi angkutan umum, kinerja adalah suatu hal yang penting untuk mengevaluasi operator angkutan umum, bukan hanya tentang profitabilitas, namun juga loyalitas serta ketertarikan penumpang dalam menggunakan angkutan umum tersebut di masa kini serta masa yang akan datang. Dari hasil analisis, terdapat 15 parameter yang berpengaruh secara signifikan terhadap hasil kepuasan mahasiswa. Hal ini ditunjukkan dengan angka korelasi yang sangat tinggi untuk setiap parameter terhadap hasil kepuasan mahasiswa. Di dalam kasus Trans Metro Pekanbaru dalam kelompok mahasiswa komuter, kualitas pelayanan dapat dinilai dari persepsi penumpang dengan menggunakan tiga faktor. Faktor pelayanan waktu menjadi faktor pelayanan yang harus segera dievaluasi oleh pihak Trans Metro karena performanya yang masih rendah dari ekspektasi atau kebutuhan dari penumpang. Selain itu, faktor teknis pelayanan Trans Metro Pekanbaru dapat dikatakan telah memenuhi kebutuhan konsumen, namun di masa yang akan dating hal ini masih perlu diperbaiki dan ditingkatkan performanya. Di satu sisi, dari segi pelayanan karyawan, kebutuhan penumpang dari segi kelompok mahasiswa telah mampu dipenuhi oleh pihak Trans Metro dengaan sangat baik, sehingga parameter ini dapat diabaikan untuk salah satu penentu kualitas pelayanan Trans Metro Pekanbaru, namun untuk masa yang akan dating masih diperlukan evaluasi kembali karena pelayanan jasa bersifat terus menerus dan menghasilkan sesuatu yang berbeda dengan pelayanan suatu produk yang cenderung monoton.

\section{Saran}

Secara umum, penelitian ini memiliki tujuan untuk mengetahui apa saja dampak peningkatan kinerja untuk kesediaan masyarakat menggunakan suatu layanan dari perusahaan. Pembatasan penelitian ini berisi kelompok mahasiswa sebagai salah satu segmen pasar Trans Metro dan aktivitas komuter sebagai suatu jenis aktivitas dari pelanggan. Di tingkat global, dalam penentuan kualitas pelayanan jasa harus dilakukan di semua segmen pasar. Kami menyarankan bahwa penelitian lebih lanjut akan menjadi lebih difokuskan terhadap segmen pasar yang berbeda, dan diperlukan parameter lain yang diperlukan seperti ekspektasi konsumen, dan harapan konsumen di masa kini dan masa yang akan datang terkait pelayanan jasa Trans Metro Pekanbaru.

\section{UCAPAN TERIMA KASIH}

Penulis mengucapkan terima kasih yang sebesar-besarnya kepada Kementerian Pendidikan Tinggi (Dikti) Republik Indonesia, Universitas Gadjah Mada serta Universitas Islam Riau untuk seluruh dukungan yang diberikan. 


\section{DAFTAR PUSTAKA}

Albalate,D. and G.Bel. (2010). "What shapes local public transportation in Europe?Economics, mobility, Institutions and Geography". Transport Res.Part E,46: 775-790.

Baglin, J. (2014). Improving your exploratory factor analysis for ordinal data: a demonstration using FACTOR. Practical Assessment, Research \& Evaluation,19(5), 2.

Budiono, O. A., \& Malkhamah, I. S. (2009). Customer satisfaction in public bus transport:: A study of travellers perception in Indonesia (Doctoral dissertation, Universitas Gadjah Mada).

Choocharukul, K., \& Sriroongvikrai, K. 2013. Multivariate analysis of customer satisfaction: a case study of Bangkok's mass rapid transit (MRT) passengers. Journal of the Eastern Asia Society for Transportation Studies, 10(0), 1258-1269.

Devi, Mutiasari Kurnia. 2015. "Active Commuting to the University (Case Study : Students of Gadjah Mada University)". Magister Thesis, Magister Program of Gadjah Mada University.

Eriksson, Lars. (2011). Car Users' Switching to Public Transport for the Work Commute, Dissertation at Faculty of Economic Sciences, Communication and IT Psychology, Karlstad University

Gerike, Regine., Hulsmann, Friederike., Roller,Katrin. 2013. " Strategies for Sustainable Mobilities: Opportunities and Challenges". Farnham, U.K. and Burlington, Vermont: Ashgate Publishing. Hafis, A., Imam, R., Hakim, A., \& Santoso Haryono, B. (2014). Aktor Pelaksana Pengelolaan Transportasi Publik Perkotaan (Studi Kasus Bus Trans Metro Di Kota Pekanbaru). WACANA, Jurnal Sosial dan Humaniora, 16(4), 171-178.

Hair, J.F. Jr. , Anderson, R.E., Tatham, R.L., \& Black, W.C. (2010). "Multivariate Data Analysis, (7th Edition)”. Upper Saddle River, NJ: Prentice Hall.

Irawan, M. Z., \& Sumi, T. (2011). Promoting active transport in students' travel behaviour: a case from Yogyakarta
(Indonesia). Journal of Sustainable Development, 4(1), 45.

Joewono, T. B., \& Kubota, H. (2007). User satisfaction with paratransit in competition with motorization in indonesia: anticipation of future implications. Transportation, 34(3), 337354.

Kenworthy,Jeffrey. (2014). "Sustainable Transport for Sustainable Cities: An International Perspective and Selected Trends". Presented to: Transportation Transformation: Do we have to choose between environment and economy?, European Parliament, Brussels. 12 February, 2014

Litman, Todd . (2010). "Evaluating Public Transportation Health Benefits". <http://www.apta.com/resources/reportsan dpublications/Documents/APTA_Health_

Benefits_Litman.pdf $>\quad$ Retrieved 31.01.2016

Martilla, J. A., \& James, J. C. (1977). Importance-performance analysis. Journal of Marketing, 41(1), 77\}79.

Munawar, A. (2006). Public transport reform in indonesia, a case study in the city of Yogyakarta. International Journal of Social Sciences, 1(3).

Panjaitan, A. M. (2013). Kajian Sistem Jaringan Jalan di Wilayah Kota Pekanbaru. Jurnal Teknik Sipil USU, 2(1) Parasuraman, A., Zeithaml, V. A., \& Berry, L. L. (1990). Delivering quality service: Balancing customer perceptions and expectations. Simon and Schuster.

Pedersen, T., Friman, M., \& Kristensson, P. (2011). Affective Forecasting: Predicting and Experiencing Satisfaction With Public Transportation. Journal of Applied Social Psychology, 41(8), 19261946.

Saputra, Parada Afkiki Eko. (2011). Evaluasi Kinerja Simpang Tiga Bersinyal Jalan Sudirman-Jalan Tuanku Tambusai Pekanbaru.S1 Thesis. Atma Jaya University, Yogyakarta.

Steg, L., Geurs, K., \& Ras, M. (2001). The effects of motivational factors on car use: a multidisciplinary modelling approach. 
Optimalisasi Jasa Antar Koridor Pelayanan Trans Metro Pekanbaru

Berbasis Persepsi Penumpang (Muchammad Zaenal Muttaqin)

Transportation Research Part A, 35, 789-

806.

Sultana, S., \& Rana, S. (2010). ".Master

Thesis in Business Administration.Master

International Management of Gotland University.

Susanto,H. (2013).Sepi, jumlah penumpang Bus TMP seperempat dari target. Riau Terkini [online]. Available at : http://www.riauterkini.com/usaha.php?arr= 64660 [Accessed 5 Mar. 2016]

Wati. (2013).Pelayanan Trans Metro dikeluhkan. Tribun Pekanbaru [online].

Available

at:

http://pekanbaru.tribunnews.com/2013/01/

09/pelayanan-trans-metro-dikeluhkan

[Accessed 5 Mar. 2016]

Uma Sekaran. 2006. Metode Penelitian

Bisnis. Jakarta : Salemba Empat.

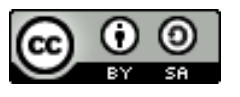

This is an open access article which means that all content is freely available without charge to the user or his/her institution. Jurnal Saintis allows the author(s) to hold the copyright without restriction. The copyright in the text of individual articles (including research articles, opinion articles, and abstracts) is the property of their respective authors distributed under the terms of the Creative Commons Attribution-ShareAlike 4.0 International License(https://creativecommons.org/licenses/by-sa/4.0/) which permits unrestricted use, distribution, and reproduction in any medium. Users are allowed to read, download, copy, distribute, search, or link to full-text articles in this journal without asking by giving appropriate credit, provide a link to the license, and indicate if changes were made. 
J. Saintis Volume 18 Nomor 1, 2018

Halaman ini sengaja di kosongkan 